\title{
Impact of Trauma-Informed Training and Mindfulness-Based Social-Emotional Learning Program on Teacher Attitudes and Burnout: A Mixed-Methods Study
}

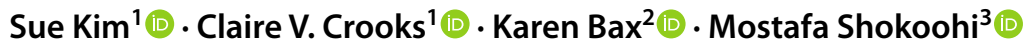

Accepted: 29 December 2020 / Published online: 9 January 2021

(c) The Author(s) 2021

\begin{abstract}
A trauma-informed approach can give teachers the strategies they need to help children affected by trauma reach their full potential in the classroom. Mindfulness-based social-emotional learning (SEL) programs equip teachers with essential tools to create a trauma-informed classroom, which in turn helps alleviate stress associated with supporting trauma-impacted children. Because existing research on SEL programs has predominantly focused on student well-being, there is a paucity of research examining teacher outcomes and the integration of a trauma-informed framework. The purpose of the study was to investigate the benefits of trauma-informed training and MindUP delivery on educator attitudes and burnout. Intervention educators received trauma-informed and MindUP training and implemented MindUP in their classrooms. Comparison educators did not participate in training and taught their usual curriculum. We compared trauma-informed attitudes and burnout levels among 112 educators ( $n=71$ intervention, $n=41$ comparison) using the Attitudes Related to Trauma-Informed Care (ARTIC) scale and the Maslach Burnout Inventory. Pre- and post-intervention quantitative data were augmented by qualitative focus group data. Results showed that educators in the intervention group reported significant decreases in emotional exhaustion, and significant improvements in the reactions subscale and overall scores on the ARTIC scale. Greatest improvements in self-efficacy and personal accomplishment were observed among educators who implemented MindUP for two consecutive years. These findings were supported by focus group data. Our results show that infusing trauma-informed training with an existing mindfulness-based SEL intervention may encourage teachers to embrace trauma-sensitive attitudes and reduce burnout.
\end{abstract}

Keywords Trauma $\cdot$ Social and emotional learning $\cdot$ Mindfulness $\cdot$ Teacher attitudes $\cdot$ Teacher burnout

\section{Introduction}

Given that approximately half of new teachers in the USA leave the profession within the first five years due to burnout, there is an urgent need for resources to support teacher well-being (Ingersoll, Merrill, Stuckey, \& Collins, 2018). Maslach, Jackson, Leiter, Schaufeli and Schwab (1996)

Claire V. Crooks

ccrooks@uwo.ca

1 Centre for School Mental Health, Western University, London, ON, Canada

2 Mary J. Wright Research and Education Centre, Western University, London, ON, Canada

3 Dalla Lana School of Public Health, University of Toronto, Toronto, ON, Canada identified emotional exhaustion, the feeling of being emotionally drained from one's work, as the initial aspect of burnout syndrome in teachers. Researchers have found that one of the significant predictors of emotional exhaustion in teachers is disruptive student behavior (Skaalvik \& Skaalvik, 2011). Emotional exhaustion triggered by discipline problems is negatively related to job satisfaction, and both emotional exhaustion and job satisfaction are predictive of teachers' motivation to leave the profession. Similarly, previous studies indicate that managing troublesome behavior in the classroom is a significant contributor to teacher stress and emotional exhaustion, as well as low self-efficacy, enthusiasm, and job satisfaction (Aldrup, Klusmann, Lüdtke, Göllner, \& Trautwein, 2018; Collie, Shapka, \& Perry, 2012).

Chronic emotional exhaustion in teachers also threatens instruction quality and students' school functioning. Oberle and Schonert-Reichl (2016) examined the connection 
between teacher burnout levels and students' physiological stress response and found that higher levels of teacher burnout are associated with higher cortisol levels in students. In addition to stress contagion threatening the classroom climate, teachers who experience high stress are more likely to resort to punitive strategies when managing challenging behavior. The teacher's inability to de-escalate situations reinforces student misbehavior, which in turn, further exacerbates symptoms of teacher stress (Osher et al., 2008). A promising way to break this stress cycle is by preparing teachers to manage behavioral challenges in the classroom, which is associated with higher self-efficacy and lower burnout (Pas, Bradshaw, \& Hershfeldt, 2012). The findings signify the importance of providing teachers with proactive classroom management strategies to enable them to create an orderly learning environment and alleviate stress.

\section{Adversity-Affected Students}

Due to the high prevalence of childhood trauma and adversity, coupled with the lack of trauma-informed training available to teachers, supporting adversity-affected students can be a source of amplified teacher stress. Children exposed to trauma or adversity often have disrupted self-regulatory and attachment capacities that may manifest as disorganized behavior in the classroom (Brunzell, Stokes, \& Waters, 2016). Without adequate training, teachers may fail to identify the underlying causes of disruptive behaviors, despite the students' attempts to convey distress through these behaviors. Teachers may respond to these misbehaviors by using control-focused, disciplinary actions that may be triggering for adversity-affected students, which further aggravates their symptoms of chronic stress (Chafouleas, Johnson, Overstreet, \& Santos, 2016). Conversely, person-centered teacher attitudes and behaviors (e.g., empathy, warmth, and ability to adapt to individual differences) are associated with a reduction in disruptive behaviors (Cornelius-White, 2007). Trauma-informed schools are needed to build staff capacities to positively impact adversity-affected children.

\section{The Need for a Trauma-Informed Approach}

Trauma-informed professional development training has been demonstrated to help teachers develop trauma-sensitive attitudes to build a classroom environment that is responsive to the needs of traumatized students (Dorado, Martinez, McArthur, \& Leibovitz, 2016; McIntyre, Baker, \& Overstreet, 2019). After implementing a trauma-informed program, Dorado et al. (2016) found reductions in referrals to the office for disciplinary actions. The findings showed that teachers were better able to defuse defiant behavior before resorting to traditional disciplinary procedures. Another study showed that teachers felt more confident in de-escalating classroom disturbances and responded to behavioral issues with compassion after participating in a trauma-informed program (Shamblin, Graham, \& Bianco, 2016). The studies suggest the potential benefits of implementing a trauma-informed framework in schools to prevent an adverse learning environment and alleviate teacher burden.

\section{Conceptual Fit Between Trauma-Informed Approach, Mindfulness, and SEL}

Trauma-informed training provides foundational information that creates a new outlook on student misbehavior. Information about the vital importance of a caring and trusting teacher-student relationship and neuroscience information about the effects of trauma on the developing brain can lead to that paradigm shift of student behavior. However, for the best result, it needs to be supplemented with an existing initiative that can permit teachers to apply newly learned trauma-informed knowledge to a classroom setting (Dorado et al., 2016). Chafouleas et al. (2016) suggested delivering trauma-informed care within a multitiered framework of school-based services, since it is harder to sustain, obtain buy-in for, and satisfy school staff's diverse interests with a single intervention. Reinbergs and Fefer (2017) identified social-emotional learning (SEL) curriculums as a potential tier 1 intervention that can augment trauma-informed training.

As Brunzell et al. (2016) noted, trauma-informed training encourages teachers to repair adversity-affected students' deficient self-regulatory capacities and attachment difficulties through engaging in co-regulation of emotions and establishing secure teacher-student attachment. To accomplish this, SEL programs can provide tools that teachers can use to promote these social-emotional capacities (Lawlor, 2016). After teachers implemented MindUP, a program that equips teachers with SEL strategies, students exhibited increased emotional control, prosocial behavior, peer acceptance, and reduced aggression (Schonert-Reichl et al., 2015). Further, a growing body of research has shown that mindfulness-based interventions can also help enhance selfregulation and social skills in adversity-affected students. For example, Ortiz and Sibinga (2017) showed that mindfulness interventions can help mitigate behavioral consequences of trauma by enhancing emotional regulation (e.g., decreased self-hostility and somatization) and school adaptation (e.g., increased social skills and classroom behavior). The compatibility of these distinct approaches suggests that mindfulness-based SEL supports a trauma-informed framework. Mindfulness-based SEL provides teachers with the skills needed to respond to disruptive classroom behavior that is likely related to past trauma. The potential benefits of integrating a trauma-informed framework into an existing 
mindfulness-based SEL intervention are an important area of study.

\section{Teacher Benefits of Mindfulness-Based SEL Programs}

In addition to the benefits of trauma-informed training on teacher well-being, implementing a mindfulness-based SEL program can help teachers further buffer the effects of stress. Meiklejohn et al. (2012) identified the direct and indirect effects of integrating mindfulness programs into the regular curriculum. Besides directly teaching a mindfulness-based SEL program to students, teachers can take advantage of the indirect effects by practicing and modeling the skills they are endorsing. de Carvalho, Pinto and Marôco (2017) found that most teachers who implemented MindUP, a mindfulnessbased SEL program, scored higher than the comparison group in self-awareness, awareness of surroundings, and personal accomplishment. Zinsser, Christensen and Torres (2016) also found that teachers who taught in educational settings that implemented SEL programs felt more supported in handling challenging behaviors and experienced higher job satisfaction. The findings suggest that mindfulness-based SEL programs may benefit not only the students, but also the teachers who are delivering the program.

\section{Current Study}

To date, most research on SEL programs has focused on student outcomes. The current study was conducted as part of a larger research project, in which we have found that MindUP, a mindfulness-based SEL program, reduces behavioral symptoms and executive functioning deficits, and improves adaptive skills in children (see Crooks, Bax, Delaney, Kim, \& Shokoohi, 2020, for more information). We believe that there is a potential for teachers to also benefit from implementing SEL programs. It has been recommended that researchers investigate teacher well-being as a result of implementing an SEL program, and evaluate the impact of trauma-informed training (Baker, Brown, Wilcox, \& Overstreet, 2015; Schonert-Reichl et al., 2015). To address both gaps in research, we examined how participation in trauma-informed training and implementation of MindUP affects educators' attitudes and burnout levels. We used a mixed-methods approach to obtain more comprehensive responses to the following research questions: (1) Do educators in the intervention group show a greater improvement in trauma-informed attitudes and reduction in burnout levels at post-test relative to educators in the comparison group? (2) Within the intervention group, do educators with two years of experience with training and MindUP have additional gains compared to educators with one year of experience? This second question was considered more exploratory in nature, but previous work with SEL programming has shown that educators implement programs with higher fidelity after a year of practice (e.g., Crooks, Chiodo, Zwarych, Hughes, \& Wolfe, 2013; Exner-Cortens, Spiric, Crooks, Syeda, \& Wells, 2020). Similarly, teachers' comfort level in teaching SEL is negatively associated with stress and positively associated with job satisfaction (Collie et al., 2012). Further, human-centered design concepts underscore the importance of familiarity with an innovation in individuals' comfort and acceptability (Lyon, Koerner, \& Chung, 2020). We expected more growth in trauma-informed attitudes and bigger decreases in burnout levels among educators in the intervention groups, and greater changes among those with two years of experience with training and MindUP.

\section{Methods}

\section{Participants}

Educators within a public school district located in Southwestern Ontario, participated in the study. School district officials selected schools based on the presence or absence of ongoing research studies, administrator and staff's willingness to implement an SEL program, and Social Risk Index (SRI) scores. This particular school district determines SRI scores based on socio-economic risk factors, including parental education, employment rate, and income; higher SRI scores are indicative of higher levels of risk. During the 2016-2017 pilot year, eight intervention schools were invited to participate in the study (see Crooks et al., 2020, for more information on school selection). A total of 26 educators (14 teachers and eight early childhood educators) from the pilot schools, received a half-day trauma-informed training, two full-days of MindUP training, and implemented MindUP in their classrooms. This cohort of educators implemented MindUP for two consecutive years, throughout the 2016-2017 and 2017-2018 school years; hence the group name, involved-twice. To scale up the evaluation following a successful pilot year, two additional intervention schools and seven comparison schools were invited to participate in the study at the beginning of the 2017-2018 school year. A total of 45 educators ( 37 teachers and eight early childhood educators) were recruited from the pilot and newly added intervention schools. These individuals attended both trauma-informed and MindUP training, and incorporated MindUP into their teaching practices for one year, during either the 2017-2018 or 2018-2019 school year; hence the group name, involved-once. Additionally, 41 educators (27 teachers and 14 early childhood educators) were recruited from the comparison schools and were assigned to the comparison group, either during the 2017-2018 or 2018-2019 school year. These individuals did not participate in either 
Table 1 Descriptive statistics overall and by the three study groups at baseline $(N=112)$

\begin{tabular}{|c|c|c|c|c|c|}
\hline & Overall & Comparison group & Involved-once & Involved-twice & $p$ value \\
\hline$N$ & 112 & 41 & 45 & 26 & - \\
\hline Sex & & & & & $.309^{c}$ \\
\hline Males & $7(6.3)^{\mathrm{a}}$ & $3(7.3)$ & $4(8.9)$ & $0(0)$ & \\
\hline Females & $105(93.7)$ & $38(92.7)$ & $41(91.1)$ & $26(100)$ & \\
\hline Ethnicity/race & & & & & $.437^{\mathrm{c}}$ \\
\hline White/Caucasian & $101(92.7)$ & $38(92.7)$ & 43 (95.6) & $20(87.0)$ & \\
\hline Other ethnicities & $8(7.3)$ & $3(7.3)$ & $2(4.4)$ & $3(13.0)$ & \\
\hline Education & & & & & $.353^{c}$ \\
\hline Completed college & $27(25.0)$ & $13(31.7)$ & 7 (15.6) & $7(31.8)$ & \\
\hline Completed Bachelor & $70(64.8)$ & $24(58.5)$ & $32(71.1)$ & $14(63.6)$ & \\
\hline Completed MA/PhD & $11(10.2)$ & $4(9.8)$ & $6(13.3)$ & $1(4.6)$ & \\
\hline Income levels & & & & & $.119^{c}$ \\
\hline$\$ 20-40 \mathrm{~K}$ & $23(21.7)$ & $11(26.8)$ & $6(14.0)$ & $6(27.3)$ & \\
\hline$\$ 41-60 \mathrm{~K}$ & $22(20.8)$ & $6(14.6)$ & $14(32.6)$ & $2(9.1)$ & \\
\hline$>\$ 60 \mathrm{~K}$ & $61(57.6)$ & $24(58.5)$ & $23(53.5)$ & $14(63.6)$ & \\
\hline Current job role & & & & & $<.001^{\mathrm{c}}$ \\
\hline Kindergarten teacher & $44(40.7)$ & 18 (43.9) & $12(26.7)$ & 14 (63.6) & \\
\hline Kindergarten early childhood educator & $30(27.8)$ & $14(34.2)$ & $8(17.8)$ & $8(36.4)$ & \\
\hline Grade $1,2,3$ & $34(31.5)$ & $9(21.9)$ & $25(55.5)$ & $0(0)$ & \\
\hline Duration in the current job role (years), mean [SD] & $7.9[7.9]^{\mathrm{b}}$ & $8.2[6.9]$ & $7.3[9.0]$ & $8.4[7.6]$ & $.815^{\mathrm{d}}$ \\
\hline Duration of working in the current organization (years), mean [SD] & $10.9[8.6]$ & $11.0[7.6]$ & $10.3[9.9]$ & $12.0[7.6]$ & $.781^{\mathrm{d}}$ \\
\hline Duration of working in the current field (years), mean [SD] & $15.2[9.1]$ & $16.0[8.3]$ & $12.4[9.9]$ & $19.4[7.1]$ & $.010^{\mathrm{d}}$ \\
\hline
\end{tabular}

${ }^{a}$ Data are expressed as $N(\%)$ unless otherwise specified

${ }^{\mathrm{b}}$ Data are expressed as mean [SD]

${ }^{\mathrm{c}}$ Using Chi-square test

${ }^{\mathrm{d}}$ Using a one-way ANOVA test

training and taught the regular curriculum. For equity of services, the comparison educators were offered the training and resources to implement MindUP the following school year. The entire sample consisted of 112 educators (involved-twice: $n=26 ; 23.2 \%$, involved-once: $n=45$; $40.2 \%$, comparison: $n=41 ; 36.6 \%$ ) over three consecutive school years (September 2016-June 2019).

Table 1 shows the descriptive statistics of the entire sample categorized into the three study groups. The majority of the participants were female $(93.7 \%)$, with $92.7 \%, 91.1 \%$, and $100 \%$ in the comparison, involved-once, and involvedtwice groups, respectively. Likewise, participants who were White/Caucasian comprised a large proportion of the entire sample (92.7\%), with $92.7 \%, 95.6 \%$, and $87.0 \%$ in the three study groups, respectively. The highest attained education level was also not statistically different across the study groups, with approximately two-thirds $(64.8 \%)$ of participants having completed a Bachelor's degree. More than half of the sample (57.6\%) reported having an income level of more than $\$ 60 \mathrm{~K}$ yearly, with no statistical difference across the study groups. For their current job role, $40.7 \%, 27.8 \%$, and $31.5 \%$ of the participants reported being kindergarten teachers, kindergarten early childhood educators, and grade 1-3 teachers, respectively. The proportion of the current job role was statistically different across the study groups: more kindergarten teachers were in the comparison group (43.9\%) and involved-twice group (63.6\%), while more grade 1-3 teachers were in the involved-once group (55.5\%).

The mean [SD] of the duration in the current job role was 7.9 [7.9] years, and working in the current organization was 10.9 [8.6] years in the whole sample, with no statistical differences in the distribution of these covariates across the study groups. The mean [SD] duration of working in the current field in the whole sample was 15.2 [9.1] years, with a longer duration in the involved-twice group (19.4 [7.1]) when compared with the comparison group (16.0 [8.3]) and involved-once group (12.4 [9.9]).

\section{Procedure}

\section{Intervention}

Intervention educators participated in a half-day in-person training on trauma-informed practice. In line with several 
Fig. 1 Study flowchart. ${ }^{\mathrm{a}}$ Group 1: This group, with more than one follow-up data, was called "involved-twice." T0a data was used as the baseline and T1b follow-up data was used as the endpoint for this group. LTFU indicates a loss to follow-up;

${ }^{\mathrm{b}}$ Groups 2 and 4 were combined to form one single group called "involved-once"; "Groups 3 and 5 were combined to form one single group called "comparison."

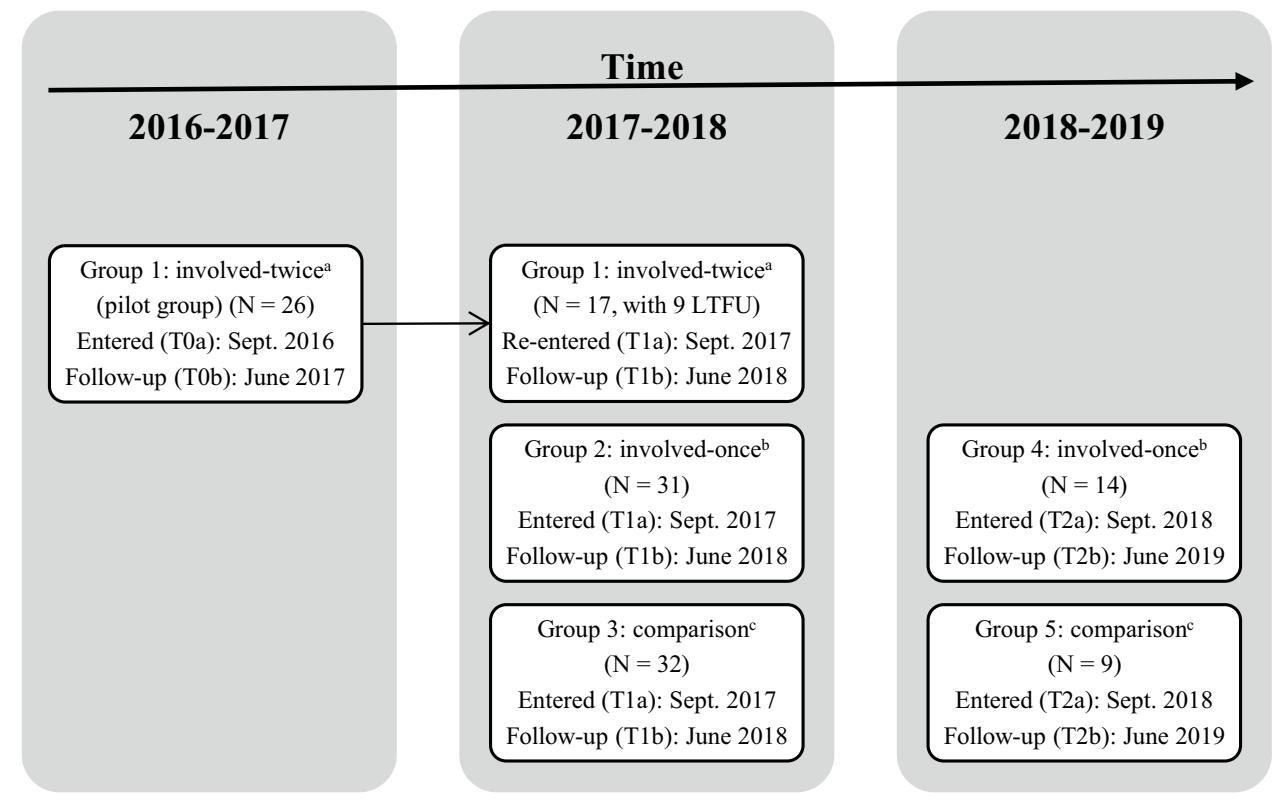

core components of trauma-informed training highlighted by McIntyre et al. (2019), the training offered through this study addressed the following topics: prevalence and impact of trauma and adversity, the neurobiology of toxic stress, stress-related behaviors in the classroom, classroom management techniques, and school staff wellness to prevent vicarious traumatization.

In addition to the trauma-informed training, intervention educators participated in a full-day in-person MindUP training in the fall and a full-day extension training in the spring. The MindUP training was facilitated by a trainer affiliated with the Goldie Hawn Foundation, the developers of the MindUP program. Through demonstrations, discussions, interactive activities, and implementation planning for each MindUP lesson, the educators learned strategies to deliver MindUP in their classrooms.

Intervention educators had the opportunity to implement MindUP in their classrooms during the school year. MindUP is a manualized program for students in pre-kindergarten to grade 8 that integrates neuroscience, mindful awareness, positive psychology, and SEL. The four themes are addressed in four separate units: (1) Getting Focused (learn the functions of brain parts, the difference between mindful and unmindful behavior, and how to perform a breathing exercise), (2) Sharpening Your Senses (practice mindful listening, seeing, smelling, tasting, and movement), (3) It's All About Attitude (consider others' viewpoints, cultivate optimism, and appreciate happy experiences), (4) Taking Action Mindfully (express gratitude and perform acts of kindness). Within the units are 15 teacher-led lessons taught once a week for approximately 40 min each (Crooks et al., 2020). Beyond the lessons, teachers are encouraged to implement the core practice of MindUP (i.e., brain break), a mindful breathing exercise, three times per day. During the brain break, students focus their attention on their breathing while listening to a chime rung by the teacher.

\section{Data Collection}

At the beginning of the school year, educators in the selected schools were given a letter of information and consent form outlining their roles as research participants. Those who consented to participate completed pre-implementation measures in September and post-implementation measures in June of the same school year. The timeline was consistent throughout the three consecutive school years. Educators in the involved-twice group were recruited in September 2016 (T0a) and followed until June 2018 (T1b), with initial follow-up in June 2017 (T0b) and re-entering in September 2017 (T1a). ${ }^{1}$ Nine educators were lost to follow-up at T1b, due to transferring to schools that are not part of the research study or switching to non-targeted grades. ${ }^{2}$ Educators in the involved-once and comparison groups were either recruited in September 2017 (T1a) and followed until June 2018 (T1b), or recruited in September 2018 (T2a) and followed until June 2019 (T2b). T1a and T2a data were combined to create the baseline, pre-implementation time period for each involved-once and comparison group, and $\mathrm{T} 1 \mathrm{~b}$ and $\mathrm{T} 2 \mathrm{~b}$ data were combined to form the follow-up, post-implementation

\footnotetext{
1 T0 $=2016-2017$ school year, $\mathrm{T} 1=2017-2018$ school year, $\mathrm{T} 2=2018-2019$ school year, $\mathrm{a}=$ pre-implementation, $\mathrm{b}=$ post-implementation.

${ }^{2}$ Specific grades were targeted each year: 2016-2017=Kindergarten, 2017-2018=Kindergarten/Grade 1, 2018-2019= Grade 1/Grade 2.
} 
time period for each involved-once and comparison group. Figure 1 shows a flowchart depicting the timeline of the three groups in this study. Intervention educators were required to complete the pre-implementation measures prior to receiving trauma-informed and MindUP training in October. Post-implementation measures and focus groups were conducted with intervention educators after MindUP implementation was complete. Comparison educators completed the pre- and post-implementation measures at similar time points. Participants received compensation for completing the surveys and the focus groups. The study procedures were approved by the Western University Research Ethics Board and the school district research department.

\section{Measures}

\section{Attitudes Related to Trauma-Informed Care (ARTIC) Scale}

The 35-item education version of the Attitudes Related to Trauma-Informed Care (ARTIC) scale was used to assess educators' trauma-informed attitudes (Baker et al., 2015). The ARTIC scale measures five core aspects of trauma-sensitive attitudes. Educators rated the items on a 7-point bipolar Likert scale with an attitude descriptor anchoring each end of the scale. Higher scores on the subscales represent a higher endorsement of trauma-informed attitudes. The scales include: (a) Underlying Causes of Problem Behavior and Symptoms (Underlying Causes; e.g., favorable attitude: "Students' learning and behavior problems are rooted in their history of difficult life events," unfavorable attitude: "Students' learning and behavior problems are rooted in their behavioral or mental health condition"), (b) Responses to Problem Behavior and Symptoms (Responses; e.g., favorable attitude: "Focusing on developing healthy, healing relationships is the best approach when working with people with trauma histories," unfavorable attitude: "Rules and consequences are the best approach when working with people with trauma histories"), (c) On-the-Job Behavior (Job Behavior; e.g., favorable attitude: "Being upset doesn't mean that students will hurt others," unfavorable attitude: "If I don't control students' behavior, other students will get hurt"), (d) SelfEfficacy at Work (Self-Efficacy; e.g., favorable attitude: "I have the skills to help my students," unfavorable attitude: "I do not have the skills to help my students"), (e) Reactions to the Work (Reactions; e.g., favorable attitude: "I have to take care of myself personally in order to take care of my students," unfavorable attitude: "How I am doing personally is unrelated to whether I can help my students"). Baker et al. (2015) established the internal consistency and validity of the ARTIC scale, and we also observed high internal consistency for the full scale in our sample $(\alpha=0.88)$. The scale has been used in some other pilot studies to evaluate trauma-informed practice (e.g., Gubi et al., 2019), and there have been calls to use more standardized measures in the evaluation of trauma-informed approaches (Purtle, 2020); however, at this point, there are not many intervention studies that have used the ARTIC scale.

\section{Maslach Burnout Inventory (MBI)}

Educators' perceived burnout levels were assessed using the Maslach Burnout Inventory (MBI; Maslach et al., 1996). The educator version of the MBI has been used extensively in research to measure burnout in professionals working in the education sector (García-Carmona, Marín, \& Aguayo, 2019). Educators can also use the MBI as a self-assessment tool and compare their scores with colleagues to gauge their stress level. Two core aspects of burnout syndrome (i.e., emotional exhaustion and lack of personal accomplishment) were measured using nine items from the Emotional Exhaustion subscale (e.g., "I feel burned out from my work") and eight items from the Personal Accomplishment subscale (e.g., "I deal very effectively with the problems of my students"). The educators reflected on the frequency of certain thoughts and behavior on a 7-point Likert scale with endpoints ranging from $0=$ never to $6=$ every day. Higher scores on the Emotional Exhaustion subscale and lower scores on the Personal Accomplishment subscale indicate higher degrees of burnout. The measure has strong psychometric properties with high internal reliability and satisfactory validity (Chang, 2013). The internal reliability in the current sample was 0.89 for the overall scale.

\section{Focus Groups}

A total of 17 semi-structured focus groups were conducted with 59 out of 71 intervention educators (83\%) across three consecutive years. The purpose of the meetings was to collect educators' perspectives on the trauma-informed training and experiences with MindUP implementation (e.g., "How have your views/ideas concerning young children changed as a result of the MindUP and trauma-informed training?" and "Have you noticed any changes in your teaching or classroom as a result of implementing the MindUP program?"). The focus groups were conducted upon completion of the MindUP program in June of each year. The meetings were held at the intervention educators' schools, in groups ranging from two to six participants, for approximately $1 \mathrm{~h}$ during lunchtime or after school.

\section{Analysis}

\section{Quantitative Analysis}

Mean and standard deviations (SD) were reported for continuous variables, and absolute and relative frequencies were 
reported for categorical variables. To compare the baseline characteristics across the three study groups, Chi-square test for categorical variables and one-way ANOVA for continuous covariates were used. Because there were no significant baseline differences across groups, paired t-tests were used to examine within-group change of the study outcomes (i.e., ARTIC and MBI subscales) in each study group from before (baseline) to after (post-intervention). One-way ANOVA was also used to compare the study outcomes across the study groups for the change scores when needed (i.e., when there were significant pre-post changes in all groups). Adjusted models using multivariable generalized estimating equation were also applied; however, we did not report them, given that there were no substantial differences relative to the unadjusted estimates (results are available upon request). Statistical analyses were performed using Stata (version 15) and SPSS (version 25).

\section{Qualitative Analysis}

The focus group conversations were audio-recorded and subsequently transcribed using Trint, an automated transcription software. The de-identified transcripts were revised and then analyzed by employing coding methods adapted from Saldaña (2016) and using Dedoose. Protocol coding method was used to assign pre-established codes (i.e., ARTIC and MBI subscales) to translate the data. The first and second authors analyzed the transcripts, and any discrepancies in interpretation were resolved through consensus. The codebook and exemplar excerpts are shown in Table 2.

\section{Results}

\section{Quantitative ARTIC Results}

Trauma-informed attitudes were investigated through the ARTIC subscales. Pre-test scores were relatively high (i.e., all groups had a mean greater than 5 on a 7-point scale), suggesting that educators rated themselves as having high levels of trauma-informed attitudes. On the Self-Efficacy subscale, groups' means were all higher than 5.5 at pre-test. For the Underlying Causes, Responses, and Job Behavior subscales, there were no statistically significant change scores from before to after the intervention in any of the study groups. For the Self-Efficacy subscale, while there were no significant change scores in the comparison group and the involved-once group, there was a significant improvement in the Self-Efficacy scores among those in the involvedtwice group (mean change: 0.44 (95\% CI [0.12, 0.76]); $p=0.007$ ). In addition, for the Reactions subscale, significant change scores were observed among the involved-once group (mean change: $0.31(95 \% \mathrm{CI}[0.09,0.52]) ; p=0.005)$ and involved-twice group (0.43 (95\% CI [0.14, 0.73]); $p=0.003$ ), while the change for the comparison group was not significant. Finally, the overall ARTIC scores significantly increased in the involved-once group (mean change: 0.20 (95\% CI [0.04, 0.36]); $p=0.016)$ and involved-twice group $(0.25$ (95\% CI $[0.09,0.41]) ; p=0.002)$, but not in the comparison group, as shown in Table 3.

\section{Qualitative Results for Trauma-Informed Attitudes}

Congruent with the significant increases in the overall ARTIC scores observed in the intervention groups, transformative stories were shared by focus group participants. In many cases, these stories reflected significant growth in the area of trauma-informed attitudes.

\section{Underlying Causes of Problem Behavior and Symptoms}

Focus group responses provided clear and specific examples of change on the Underlying Causes dimension for some participants. With newly acquired knowledge of how trauma can manifest behaviorally in the classroom, educators were able to shift their perspective and view certain rebellious behavior as stress behavior from exposure to trauma or adversity. Furthermore, they anchored their new perspective in the training experience. One educator noted, "Sometimes, something so small that normally wouldn't bother a child, [makes] this particular child just snap. From that training, you realize there's so much going on. ... It changes how you approach everything." Other educators shared that they experienced a similar shift in perspective. For example, one educator recommended pausing and reflecting on the root cause of the problematic behavior: "I still remember, from the trauma workshop, 'Why this child? Why now?' ... I say that to myself, when I have a child that's misbehaving or [being] attention-seeking." Taking this approach has allowed educators to be more "understanding and patient," "forgiving," and "compassionate." Additionally, several educators noted that the mindfulness components of MindUP had contributed to their heightened awareness and sensitivity to viewing student behavior through a trauma lens: "I've become a lot more mindful as a teacher. You always recognize those kids who have difficulty, but there's a whole different perspective now ... as to how we look at children and how we deal with them."

\section{Responses to Problem Behavior and Symptoms}

Multiple participants also highlighted the importance of responding appropriately to children who have experienced trauma and adversity. Given that many types of trauma violate children's sense of safety and lead to the inability to trust 


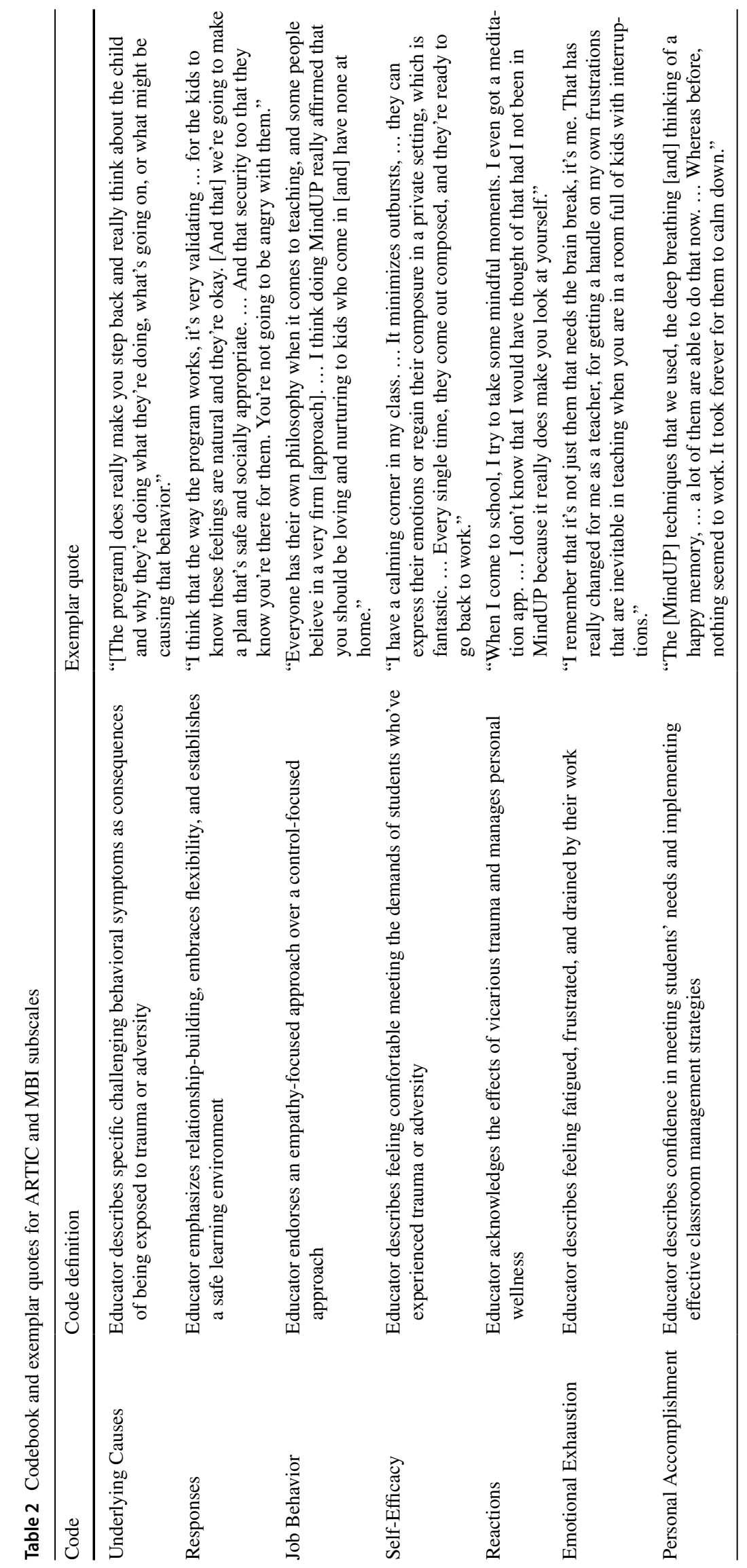


Table 3 Mean scores before and after the intervention, change scores, and multivariable model to assess the impact of the intervention on ARTIC subscales

\begin{tabular}{|c|c|c|c|}
\hline $\begin{array}{l}\text { ARTIC outcomes } \\
\left(N=85^{\mathrm{a}}\right)\end{array}$ & Comparison group & Involved-once & Involved-twice \\
\hline$N$ in each group & 36 & 35 & 14 \\
\hline \multicolumn{4}{|l|}{ Underlying causes } \\
\hline Pre-intervention mean (SD) score & $5.08(0.68)$ & $5.11(0.61)$ & $5.27(0.85)$ \\
\hline Post-intervention mean (SD) score ${ }^{b}$ & $5.29(0.73)$ & $5.25(0.68)$ & $5.32(0.87)$ \\
\hline Change score $(95 \% \mathrm{CI})$ & $\begin{array}{l}0.21 \\
(-0.03,0.45)\end{array}$ & $\begin{array}{l}0.15 \\
(-0.06,0.35)\end{array}$ & $\begin{array}{l}0.05 \\
(-0.15,0.25)\end{array}$ \\
\hline$p$ value $^{\mathrm{c}}$ & .085 & .164 & .641 \\
\hline \multicolumn{4}{|l|}{ Responses } \\
\hline Pre-intervention mean (SD) score & $5.20(0.82)$ & $5.21(0.81)$ & $5.47(0.84)$ \\
\hline Post-intervention mean (SD) score ${ }^{b}$ & $5.18(0.83)$ & $5.42(0.85)$ & $5.68(0.85)$ \\
\hline Change score $(95 \% \mathrm{CI})$ & $\begin{array}{l}-0.02 \\
(-0.23,0.20)\end{array}$ & $\begin{array}{l}0.21 \\
(-0.10,0.51)\end{array}$ & $\begin{array}{l}0.20 \\
(-0.18,0.58)\end{array}$ \\
\hline$p$ value $^{\mathrm{c}}$ & .876 & .188 & .294 \\
\hline \multicolumn{4}{|l|}{ Job behavior } \\
\hline Pre-intervention mean (SD) score & $5.31(0.69)$ & $5.43(0.58)$ & $5.67(0.79)$ \\
\hline Post-intervention mean (SD) score ${ }^{b}$ & $5.49(0.59)$ & $5.58(0.59)$ & $5.81(0.59)$ \\
\hline Change score $(95 \% \mathrm{CI})$ & $\begin{array}{l}0.18 \\
(-0.04,0.40)\end{array}$ & $\begin{array}{l}0.14 \\
(-0.05,0.33)\end{array}$ & $\begin{array}{l}0.13 \\
(-0.20,0.47)\end{array}$ \\
\hline$p$ value $^{\mathrm{c}}$ & .110 & .149 & .440 \\
\hline \multicolumn{4}{|l|}{ Self-efficacy } \\
\hline Pre-intervention mean (SD) score & $5.67(0.87)$ & $5.58(0.67)$ & $5.60(0.90)$ \\
\hline Post-intervention mean (SD) score ${ }^{b}$ & $5.82(0.74)$ & $5.80(0.78)$ & $6.03(0.85)$ \\
\hline Change score $(95 \% \mathrm{CI})$ & $\begin{array}{l}0.16 \\
(-0.07,0.39)\end{array}$ & $\begin{array}{l}0.22 \\
(-0.01,0.45)\end{array}$ & $\begin{array}{l}0.44 \\
(0.12,0.76)\end{array}$ \\
\hline$p$ value $^{\mathrm{c}}$ & .169 & .065 & .007 \\
\hline \multicolumn{4}{|l|}{ Reactions } \\
\hline Pre-intervention mean (SD) score & $5.49(0.79)$ & $5.36(0.78)$ & $5.59(0.49)$ \\
\hline Post-intervention mean (SD) score ${ }^{b}$ & $5.61(0.88)$ & $5.67(0.78)$ & $6.03(0.69)$ \\
\hline Change score $(95 \% \mathrm{CI})$ & $\begin{array}{l}0.12 \\
(-0.10,0.36)\end{array}$ & $\begin{array}{l}0.31 \\
(0.09,0.52)\end{array}$ & $\begin{array}{l}0.43 \\
(0.14,0.73)\end{array}$ \\
\hline$p$ value $^{\mathrm{c}}$ & .283 & .005 & .003 \\
\hline \multicolumn{4}{|l|}{ Overall (35 ARTIC items) } \\
\hline Pre-intervention mean (SD) score & $5.34(0.62)$ & $5.33(0.49)$ & $5.52(0.61)$ \\
\hline Post-intervention mean (SD) score ${ }^{b}$ & $5.48(0.54)$ & $5.54(0.59)$ & $5.77(0.57)$ \\
\hline Change score $(95 \% \mathrm{CI})$ & $\begin{array}{l}0.13 \\
(-0.04,0.31)\end{array}$ & $\begin{array}{l}0.20 \\
(0.04,0.36)\end{array}$ & $\begin{array}{l}0.25 \\
(0.09,0.41)\end{array}$ \\
\hline$p$ value ${ }^{c}$ & .135 & .016 & .002 \\
\hline
\end{tabular}

${ }^{a}$ Using listwise deletion (LD) approach, 85 participants were included in the final analyses

${ }^{\mathrm{b}}$ One-year follow-up for comparison and involved-once groups, 2-year follow-up for involved-twice group ${ }^{\mathrm{c}} P$ value was obtained from paired $t$-test for within-group comparisons

Bold values indicate statistical significant $(p<.05)$ others, an educator recommended establishing a supportive environment by emphasizing relationship-building:

When they come into my room,... I want to make it a safe place for them to be because, for some, it's the safest place they have. ... I'm much more likely to wonder what happened this morning. ... I'm more likely to notice and take the time to ... make a connection with each kid. ... I started doing the morning check-ins with the kids. 
One trauma-informed response to challenging student behavior is to embrace flexibility by accommodating individual needs. An educator who implemented MindUP for two consecutive years offered her advice on adjusting one's approach to meet individual needs and assisting traumatized students who may feel powerless, to exercise control:

I think this year, I'm better at not expecting every student to be perfect when we're doing brain breaks. ... We've got so many different ways of breathing and different strategies ... that they can grab what's for them and that it's not the same for everybody. ... A mindful moment doesn't look the same for every person.

\section{On-the-Job Behavior}

In contrast to survey responses, which did not show a change for the Job Behavior subscale, focus group participants expressed their changed views, from using a control-focused approach to adopting an empathy-focused approach in the classroom. An educator reflected, "At the beginning of the year, I thought that every child that had a behavioral issue had to be dealt with in one way. I've learned over the year ... that it's not always that disciplinary measure." Similarly, an educator who implemented MindUP for 2 years agreed,

One teacher scream[ed] at her kids, and I looked at her, and I went, “Oh my gosh!” It didn't make sense how she was dealing with these behaviors. I think [MindUP] really helped me see, over [the] years. I wouldn't have said this the first year.

\section{Self-Efficacy at Work}

Focus group data converged with the quantitative findings for the Self-Efficacy subscale. Two recurring themes among educators who implemented MindUP for 2 years included increased confidence in their capability to deliver the program and stronger belief that students will benefit from SEL. An educator reflected,

I wouldn't have been able to say this last year. Now that I've done it the second time, I feel much greater success with it. I ring that chime, and there is silence immediately, ... automatically they go to focusing on their breathing. ... It only takes a couple of minutes, and then they're ready to go.

Another educator in the involved-twice group shared an anecdote:
Last year, he would be flipping tables, throwing chairs, and screaming at the top of his lungs. I look at the way that he dealt with his frustration, and now I look at him. ... You can see that he's belly breathing. ... You can see that he removes himself from wherever he is; he just finds that quiet space in the classroom. ... That shows me that he is being mindful, and he's taking everything that we've taught over the last two years.

\section{Reactions to the Work}

Again, patterns observed in the focus group data for the Reactions subscale were consistent with the survey results. A common theme among educators in the intervention group was an increased interest in improving personal wellness. Educators reported engaging in self-care practices to minimize the effects of vicarious traumatization and to maintain their capacity to support students. For example, one educator reflected, "I find that if I'm having a day, where I'm forgetting to be empathetic, ... that it's me that needs to take the minute. ... I can turn it and look at me when things aren't going well." The educator added, "I benefit just as much from taking that deep breath, taking that brain break." Other educators agreed that the brain breaks have helped them be "more mindful and calmer" and "more conscious and aware of what [they] needed to do [next]." Another educator recommended "taking a pause ... and taking deep breaths. That's something that I never did. ... [MindUP] has caused me to go, ... 'It's okay to wait a few minutes instead of jumping into something."'.

\section{Quantitative MBI Results}

Within-group comparisons showed that the mean score of Emotional Exhaustion was significantly reduced in the involved-once group only (mean change: -0.41 (95\% CI $[-0.76,-0.06]) ; p=0.021)$, while there were no statistically significant changes in the comparison group and involved-twice group. Regarding the Personal Accomplishment subscale, within-group comparisons showed that the mean scores significantly improved in all three study groups, with greater improvements in the involved-twice group. On average, mean change in the comparison group was 0.27 (95\% CI $[0.07,0.47] ; p=0.008)$, in the involvedonce group was 0.32 (95\% CI $[0.09,0.55] ; p=0.007)$, and in the involved-twice group was 1.27 (95\% CI [0.99, 1.54]; $p<0.001)$. Given the significant findings in each group, oneway ANOVA test was used to compare the change scores across the three study groups. This ad hoc analysis showed that the change scores across these three groups were different $\left(F\right.$ test $\left._{(2,83)}=14.32 ; p<0.001\right)$. A Bonferroni post hoc test was used to look at differences in the specific pairs of groups. Change scores for the comparison and involved-once groups were not significantly different from each other, and 
Table 4 Mean scores before and after the intervention, change scores, and multivariable model to assess the impact of the intervention on MBI subscales

\begin{tabular}{|c|c|c|c|}
\hline $\begin{array}{l}\text { MBI outcomes } \\
\left(N=86^{\mathrm{a}}\right)\end{array}$ & Comparison group & Involved-once & Involved-twice \\
\hline$N$ in each group & 36 & 35 & 15 \\
\hline \multicolumn{4}{|l|}{ Emotional exhaustion } \\
\hline Pre-intervention mean (SD) score & $2.31(1.3)$ & $2.75(1.4)$ & $2.01(1.2)$ \\
\hline Post-intervention mean (SD) score ${ }^{b}$ & $2.25(1.4)$ & $2.34(1.5)$ & $1.75(1.4)$ \\
\hline Change score $(95 \% \mathrm{CI})$ & $\begin{array}{l}-0.07 \\
(-0.38,0.24)\end{array}$ & $\begin{array}{l}-0.41 \\
(-0.76,-0.06)\end{array}$ & $\begin{array}{l}-0.26 \\
(-0.80,0.28)\end{array}$ \\
\hline$p$ value $^{\mathrm{c}}$ & 666 & .021 & .346 \\
\hline \multicolumn{4}{|l|}{ Personal accomplishment } \\
\hline Pre-intervention mean (SD) score & $5.05(0.78)$ & $4.89(0.69)$ & $4.16(0.54)$ \\
\hline Post-intervention mean (SD) score ${ }^{b}$ & $5.32(0.60)$ & $5.12(0.61)$ & $5.43(0.50)$ \\
\hline Change score $(95 \% \mathrm{CI})$ & $\begin{array}{l}0.27^{\mathrm{d}} \\
(0.07,0.47)\end{array}$ & $\begin{array}{l}0.32^{\mathrm{d}} \\
(\mathbf{0 . 0 9}, \mathbf{0 . 5 5})\end{array}$ & $\begin{array}{l}1.27^{\mathrm{d}} \\
(0.99,1.54)\end{array}$ \\
\hline$p$ value $^{\mathrm{c}}$ & .008 & .007 & $<.001$ \\
\hline \multicolumn{4}{|c|}{${ }^{a}$ Using listwise deletion (LD) approach, 86 participants were included in the final analyses } \\
\hline \multicolumn{4}{|c|}{$\begin{array}{l}{ }^{\mathrm{b}} \text { One-year follow-up for comparison and involved-once groups, 2-year follow-up for involved-twice group } \\
{ }^{\mathrm{c}} P \text { value was obtained from paired } t \text {-test for within-group comparisons }\end{array}$} \\
\hline \multicolumn{4}{|c|}{$\begin{array}{l}{ }^{\mathrm{d}} \text { Change scores were not significantly different between the comparison group and the involved-once } \\
\text { group, but the involved-twice group change score was larger than those of the other two groups }\end{array}$} \\
\hline \multicolumn{4}{|c|}{ Bold values indicate statistical significant $(p<.05)$} \\
\hline
\end{tabular}

both were smaller than for the involved -twice group, as noted in Table 4.

\section{Qualitative Results Regarding Burnout}

\section{Emotional Exhaustion}

In contrast to the survey results, feelings of being emotionally overextended and acknowledgments of the benefits of training and MindUP in alleviating stress were especially noticeable among educators in the involved-twice group. An educator noted,

It's hard for us to be mindful at times. ... Our things have been ruined, thrown everywhere, bins dumped, and we all have had to evacuate with our class. ... So there are times where I do struggle, but it's nice to have those [MindUP] tools.

Similarly, another educator in the involved-twice group shared,

I'm more relaxed. ... [When I'm] getting flustered, ... [I] remind [myself], "I just need to breathe and keep calm." ... [MindUP has] definitely helped reduce my stress. Even just the pace of how I teach. ... I remember last year, I would speak fast, and I would try to get through everything. And now it's more slowed down, and it's the quality instead of the quickness.

\section{Personal Accomplishment}

Consistent with the survey data, improvements in Personal Accomplishment were also observed in focus group responses. Educators expressed an increase in feeling competent in building an optimal educational climate by implementing effective classroom management strategies. Many educators identified brain breaks as an essential daily practice that has "made transitions between activities easier" and "help[ed] prevent behaviors from happening":

I find when behavior is escalating, ... what's missing from the day [is], we haven't done as many brain breaks. We haven't taken time for MindUP. I'm much more likely now to pause and go. That's time I need to spend because I'm going to gain it back later, with more productive work.

Additionally, many educators noticed that students' social-emotional skills (e.g., "listening capabilities," "recognition of each other's emotions," "kindness ... [and] empath[y]," and "calm[ing] down before they make a choice") were expanding as a result of MindUP. The improvements in students' social-emotional functioning further promote a non-disruptive environment that facilitates learning. Several educators also indicated that the MindUP lessons had given them the tools needed to meet students' emotional needs with confidence. For example, an educator focused on the "perspective-taking" lesson when their class had "a lot of negativity toward each other." Another 
educator suggested teaching the "optimism" lesson when a class "feels discouraged with an activity."

\section{Discussion}

This study explored the changes in educators' attitudes and burnout levels after attending trauma-informed training and MindUP training, and implementing MindUP in their classrooms. Previous research has demonstrated that teachers trained in trauma-informed practices can positively impact adversity-affected children, and teacher-led SEL programs can improve educator well-being (Dorado et al., 2016; Schonert-Reichl, 2019). The current study produced mixed findings, in that, relatively few impacts were identified through quantitative measures, whereas qualitative data from focus groups provided compelling examples of change. This study provides a preliminary evaluation of the impacts of combining a trauma-informed framework with an existing SEL program on teacher burnout.

By utilizing a mixed-methods approach, data collected through different methods were triangulated to more fully understand the complexity involved in changing attitudes in educators. In this study, both quantitative and qualitative data supported the impact of trauma-informed training and the implementation of an SEL program, MindUP, although not to the same extent. With regards to quantitative findings, significant pre-post changes and a duration effect were observed for the overall ARTIC scores and two of its subscales, in addition to the Personal Accomplishment subscale of the MBI. The qualitative results showed how the training impacted educators' knowledge of trauma and adversity, and led to meaningful changes in how educators viewed student behavior and their own responses to stress behavior. Similar to Herman and Whitaker (2020), more compelling stories of transformation emerged from the focus group conversations than quantitative scores in relation to all variables. These are preliminary results and should be repeated with a larger sample size.

In response to our first research question regarding the impact of the intervention on trauma-informed attitudes and burnout, significant changes in several aspects were observed among educators in the intervention group, while comparison educators did not demonstrate comparable changes. The Reactions scores and overall ARTIC scores increased within groups for both the involved-once and involved-twice groups, indicating greater change to endorse trauma-informed attitudes at post-intervention. Additionally, a significant reduction in Emotional Exhaustion on the MBI was observed in the involved-once group from pre- to post-intervention. It is unclear why a significant reduction in Emotional Exhaustion was not observed in the involvedtwice group.
In response to our second research question about the relative benefit for educators who had participated for two years instead of one, educators in the involved-twice group showed greatest improvements on the Self-Efficacy subscale of the ARTIC scale and the Personal Accomplishment subscale of the MBI. Collie et al. (2012) revealed that teachers' comfort level in implementing SEL is positively associated with self-efficacy and negatively associated with stress resulting from student misbehavior. Likewise, the educators in the involved-twice group may have felt more competent in meeting the demands of challenging students after becoming more familiar with the MindUP program and experiencing the benefits from the previous year of implementation. Additionally, the Personal Accomplishment subscale of the MBI showed statistically significant withingroup improvements in all three study groups, especially after two years of intervention. This indicates that educators were more confident in implementing classroom management strategies after two years of participating in training and implementing the MindUP program.

There were some overlapping inclusion criteria between the conceptually similar codes of Personal Accomplishment on the MBI and Self-Efficacy on the ARTIC scale as a result of using pre-established constructs as codes. However, there is an important difference, in that, Personal Accomplishment on the MBI is identified as more of a general feeling of making a positive difference in their students' lives, whereas Self-Efficacy on the ARTIC scale is operationalized as a feeling of confidence in being able to meet the specific demands of traumatized children. The latter is likely a more challenging attitude to change and thus, not surprising that the significant difference pre-post was found for the involved-twice group only, whereas the former, more general change was found within all three groups.

\section{Limitations and Future Directions}

There are several limitations worth noting. First, there is a potential source of selection bias for the focus groups, in that educators who were more enthusiastic about traumainformed care and MindUP might have been more likely to participate. Further, the focus groups were conducted by our research team, which might encourage participants to emphasize positive aspects of their experience (although we countered that by asking specifically for negative experiences and suggestions for improving the intervention). Additionally, educators rated their trauma-informed attitudes positively pre-intervention, suggesting that they already endorsed the attitudes targeted in the trauma-informed training. Alternatively, response-shift bias may have led to inaccurate pre-intervention survey data, in that, prior to receiving training, educators may have unintentionally under- or over-estimated their knowledge and skills (Hill 
$\&$ Betz, 2005). Their internal point of reference may have changed after receiving the training and implementing the program, resulting in biased scores. In addition, there is a lack of information on fidelity of implementation of MindUP. Although educators self-reported high rates of program completion (see Crooks et al., 2020), there are limitations with relying on self-report alone to measure implementation quality (Emerson, de Diaz, Sherwood, Waters, \& Farrell, 2020). One limitation of the combined intervention model is that we cannot disaggregate whether some of the perceived benefits were due to the trauma-informed training or MindUP alone. Finally, we did not measure comparison groups' experience with the use of mindfulness practices or SEL programs.

To better understand the effectiveness of trauma-informed training, future research should include satisfaction surveys to assess training quality. Furthermore, teachers' knowledge of trauma and comfort levels of implementing traumainformed practices, before and after the training, could be assessed. Additionally, by asking scenario questions in interviews, pre- and post-intervention data for personal support of trauma-informed care could be obtained. These data will elucidate whether educators' attitudes toward traumainformed practice change or remain stable over time.

The study contributes to a growing body of research in creating trauma-informed schools and enhancing teacher wellness. The promising results suggest that traumainformed training and MindUP implementation may help promote trauma-sensitive attitudes and reduce teacher burnout.

Acknowledgements This research was funded by a grant from the Public Health Agency of Canada. One of the authors, Mostafa Shokoohi, is also funded by the Canadian Institutes of Health Research (CIHR) Postdoctoral Fellowship. We would like to acknowledge Terry Spencer (Research and Evaluation Officer), Sandra Savage (Mental Health Lead), and the educators within the London District Catholic School Board for their contributions to the implementation of this study. We would also like to acknowledge Maisha Syeda and Eli Cwinn (Postdoctoral Associates at the Centre for School Mental Health) for reviewing an earlier draft of this paper.

Funding This study was funded by the Public Health Agency of Canada (1617-HQ-000049).

Code availability Corresponding author.

\section{Compliance with Ethical Standards}

Conflict of interest The authors declare that they have no conflict of interest.

Open Access This article is licensed under a Creative Commons Attribution 4.0 International License, which permits use, sharing, adaptation, distribution and reproduction in any medium or format, as long as you give appropriate credit to the original author(s) and the source, provide a link to the Creative Commons licence, and indicate if changes were made. The images or other third party material in this article are included in the article's Creative Commons licence, unless indicated otherwise in a credit line to the material. If material is not included in the article's Creative Commons licence and your intended use is not permitted by statutory regulation or exceeds the permitted use, you will need to obtain permission directly from the copyright holder. To view a copy of this licence, visit http://creativecommons.org/licenses/by/4.0/.

\section{References}

Aldrup, K., Klusmann, U., Lüdtke, O., Göllner, R., \& Trautwein, U. (2018). Student misbehavior and teacher well-being: Testing the mediating role of teacher-student relationship. Learning and Instruction, 58, 126-136. https://doi.org/10.1016/j.learninstr uc.2018.05.006.

Baker, C. N., Brown, S. M., Wilcox, P. D., \& Overstreet, S. (2015). Development and psychometric evaluation of the Attitudes Related to Trauma-Informed Care (ARTIC) scale. School Mental Health, 8, 61-76. https://doi.org/10.1007/s12310-015-9161-0.

Brunzell, T., Stokes, H., \& Waters, L. (2016). Trauma-informed positive education: Using positive psychology to strengthen vulnerable students. Contemporary School Psychology, 20, 63-83. https ://doi.org/10.1007/s40688-015-0070-x.

Chafouleas, S. M., Johnson, A. H., Overstreet, S., \& Santos, N. M. (2016). Toward a blueprint for trauma-informed service delivery in schools. School Mental Health, 8, 144-162. https://doi. org/10.1007/s12310-015-9166-8.

Chang, M. L. (2013). Toward a theoretical model to understand teacher emotions and teacher burnout in the context of student misbehavior: Appraisal, regulation and coping. Motivation and Emotion, 37(4), 799-817. https://doi.org/10.1007/s11031-012-9335-0.

Collie, R. J., Shapka, J. D., \& Perry, N. E. (2012). School climate and social-emotional learning: Predicting teacher stress, job satisfaction, and teaching efficacy. Journal of Educational Psychology, 104(4), 1189-1204. https://doi.org/10.1037/a0029356.

Cornelius-White, J. (2007). Learner-centered teacher-student relationships are effective: A meta-analysis. Review of Educational Research, 77, 113-143. https://doi.org/10.3102/0034654302 98563.

Crooks, C. V., Chiodo, D., Zwarych, S., Hughes, R., \& Wolfe, D. A. (2013). Predicting implementation success of an evidence-based program to promote healthy relationships among students two to eight years after teacher training. Canadian Journal of Community Mental Health, 32(1), 125-138.

Crooks, C. V., Bax, K., Delaney, A., Kim, H., \& Shokoohi, M. (2020). Impact of mindUP among young children: Improvements in behavioral problems, adaptive Skills, and executive functioning. Mindfulness, 11(10), 2433-2444. https://doi.org/10.1007/s1267 1-020-01460-0.

de Carvalho, J. S., Pinto, A. M., \& Marôco, J. (2017). Results of a mindfulness-based social-emotional learning program on Portuguese elementary students and teachers: A quasi-experimental study. Mindfulness, 8(2), 337-350. https://doi.org/10.1007/s1267 1-016-0603-z.

Dorado, J. S., Martinez, M., McArthur, L. E., \& Leibovitz, T. (2016). Healthy Environments and Response to Trauma in Schools (HEARTS): A whole-school, multi-level, prevention and intervention program for creating trauma-informed, safe and supportive schools. School Mental Health, 8, 163-176. https://doi. org/10.1007/s12310-016-9177-0.

Emerson, L. M., de Diaz, N. N., Sherwood, A., Waters, A., \& Farrell, L. (2020). Mindfulness interventions in schools: Integrity and feasibility of implementation. International Journal of Behavioral 
Development, 44, 62-75. https://doi.org/10.1177/0165025419 866906.

Exner-Cortens, D., Spiric, V., Crooks, C., Syeda, M., \& Wells, L. (2020). Predictors of healthy youth relationships program implementation in a sample of Canadian middle school teachers. Canadian Journal of School Psychology, 35(2), 100-122.

García-Carmona, M., Marín, M. D., \& Aguayo, R. (2019). Burnout syndrome in secondary school teachers: A systematic review and meta-analysis. Social Psychology of Education: An International Journal, 22, 189-208. https://doi.org/10.1007/s1121 8-018-9471-9.

Gubi, A. A., Strait, J., Wycoff, K., Vega, V., Brauser, B., \& Osman, Y. (2019). Trauma-informed knowledge and practices in school psychology: A pilot study and review. Journal of Applied School Psychology, 35(2), 176-199. https://doi.org/10.1080/15377 903.2018.1549174.

Herman, A., \& Whitaker, R. C. (2020). Reconciling mixed messages from mixed methods: A randomized trial of a professional development course to increase trauma-informed care. Child Abuse \& Neglect. https://doi.org/10.1016/j.chiabu.2019.104349.

Hill, L. G., \& Betz, D. L. (2005). Revisiting the retrospective pretest. American Journal of Evaluation, 26(4), 501-517. https://doi. org/10.1177/1098214005281356.

Ingersoll, R. M., Merrill, E., Stuckey, D., \& Collins, G. (2018). Seven trends: The transformation of the teaching force-Updated October 2018. Consortium for Policy Research in Education.

Lawlor, M. S. (2016). Mindfulness and social emotional learning (SEL): A conceptual framework. In K. Schonert-Reichl \& R. Roeser (Eds.), Handbook of mindfulness in education (pp. 65-80). Berlin: Springer. https://doi.org/10.1007/978-1-4939-3506-2_5.

Lyon, A. R., Koerner, K., \& Chung, J. (2020). Usability evaluation for evidence-based psychosocial interventions (USE-EBPI): A methodology for assessing complex intervention implementability. Implementation Research and Practice, 1, 1-17. https://doi. org/10.1177/2633489520932924.

Maslach, C., Jackson, S. E., Leiter, M. P., Schaufeli, W. B., \& Schwab, R. L. (1996). Maslach Burnout Inventory Manual (4th ed.). Menlo Park: Mind Garden.

McIntyre, E. M., Baker, C. N., \& Overstreet, S. (2019). Evaluating foundational professional development training for traumainformed approaches in schools. Psychological Services, 16, 95-102. https://doi.org/10.1037/ser0000312.

Meiklejohn, J., Phillips, C., Freedman, M. L., Griffin, M. L., Biegel, G., Roach, A., et al. (2012). Integrating mindfulness training into K-12 education: Fostering the resilience of teachers and students. Mindfulness, 3, 291-307. https://doi.org/10.1007/s1267 1-012-0094-5.

Oberle, E., \& Schonert-Reichl, K. A. (2016). Stress contagion in the classroom? The link between classroom teacher burnout and morning cortisol in elementary school students. Social
Science \& Medicine, 159, 30-37. https://doi.org/10.1016/j.socsc imed.2016.04.031.

Ortiz, R., \& Sibinga, E. M. (2017). The role of mindfulness in reducing the adverse effects of childhood stress and trauma. Children (Basel), 4(3), 16. https://doi.org/10.3390/children4030016.

Osher, D., Sprague, J., Weissberg, R. P., Axelrod, J., Keenan, S., Kendziora, K., \& Zins, J. E. (2008). A comprehensive approach to promoting social, emotional, and academic growth in contemporary schools. In A. Thomas \& J. Grimes (Eds.), Best practices in school psychology (Vol. 4, pp. 1263-1278). Bethesda: National Association of School Psychologists.

Pas, E. T., Bradshaw, C. P., \& Hershfeldt, P. A. (2012). Teacher- and school-level predictors of teacher efficacy and burnout: Identifying potential areas for support. Journal of School Psychology, 50, 129-145. https://doi.org/10.1016/j.jsp.2011.07.003.

Purtle, J. (2020). Systematic review of evaluations of trauma-informed organizational interventions that include staff trainings. Trauma Violence Abuse, 21(4), 725-740. https://doi.org/10.1177/15248 38018791304

Reinbergs, E. J., \& Fefer, S. A. (2017). Addressing trauma in schools: Multitiered service delivery options for practitioners. Psychology in the Schools, 55(3), 250-263. https://doi.org/10.1002/pits.22105.

Saldaña, J. (2016). The coding manual for qualitative researchers (3rd ed.). Thousand Oaks: SAGE.

Schonert-Reichl, K. A. (2019). Advancements in the landscape of social and emotional learning and emerging topics on the horizon. Educational Psychologist, 54(3), 222-232. https://doi. org/10.1080/00461520.2019.1633925.

Schonert-Reichl, K. A., Oberle, E., Lawlor, M. S., Abbott, D., Thomson, K., Oberlander, T. F., \& Diamond, A. (2015). Enhancing cognitive and social-emotional development through a simpleto-administer mindfulness-based school program for elementary school children: A randomized controlled trial. Developmental Psychology, 51, 52-66. https://doi.org/10.1037/a0038454.

Shamblin, S., Graham, D., \& Bianco, J. A. (2016). Creating traumainformed schools for rural Appalachia: The partnerships program for enhancing resiliency, confidence, and workforce development in early childhood education. School Mental Health, 8, 189-200. https://doi.org/10.1007/s12310-016-9181-4.

Skaalvik, E. M., \& Skaalvik, S. (2011). Teacher job satisfaction and motivation to leave the teaching profession: Relations with school context, feeling of belonging, and emotional exhaustion. Teaching and Teacher Education, 27(6), 1029-1038. https://doi. org/10.1016/j.tate.2011.04.001.

Zinsser, K. M., Christensen, C. G., \& Torres, L. (2016). She's supporting them; who's supporting her? Preschool center-level socialemotional supports and teacher well-being. Journal of School Psychology, 59, 55-66. https://doi.org/10.1016/j.jsp.2016.09.001.

Publisher's Note Springer Nature remains neutral with regard to jurisdictional claims in published maps and institutional affiliations. 